\title{
Manajemen Seleksi pada Posisi Education Administrator di Global Art Education Denpasar
}

\author{
Melissa Waturandang1, Aljuanika Ertamaya Ering² ${ }^{2}$ Hana Wulandari Mona ${ }^{3}$ \\ 1,2,3 Institut Agama Kristen Negeri Manado \\ email: melissawaturandang@iakn-manado.ac.id
}

\begin{abstract}
In the development of the world of education, education management is needed, one of which is the placement of human resources. Global Art as one of the companies engaged in the world of education requires Education Administrator staff for this reason, employee selection is carried out to fulfill the administrator position. In the selection, selection is carried out using the psychological test method or psychological examination. The research was conducted to find out how education management uses psychological tests in placing employees according to needs. Psikotest results found that prospective employees meet the requirements for the position of Education Administrator at Global Art.
\end{abstract}

Keywords: education management, selection, psychological test.

\section{PENDAHULUAN}

Globalisasi saat ini telah menjadi suatu realitas yang harus dihadapi bangsa Indonesia, pada umumnya telah memberikan suatu pengaruh yang lebih bagi kelangsungan masyarakat Indonesia, dengan begitu banyak perubahan yang terjadi secara cepat, gejalanya terlihat dari diberbagai bidang, salah satunya bidang industry dan usaha sehingga setiap perusahaan dituntut agar dengan cepat mampu beradaptasi, memiliki ketahanan, serta mampu melakukan perubahan arah. Menghadapi perubahan tersebut, salah satu kunci sukses untuk menghadapi era globalisasi dan memenangkan persaingan antar perusahaan yang semakin ketat adalah dengan cara menyediakan sumber daya manusia yang berkualitas. Ketersediaan sumber daya manusia (untuk selanjutnya SDM) yang kompeten pada bidangnya merupakan kunci suksesnya perusahaan tersebut.

Dalam mencapai tujuan agar pendidikan dapat tercapai maka perlu adanya proses manajemen Pendidikan yang baik. Manajemen adalah suatu proses yang diawali dengan perencanaan dan selanjutnya dilakukan pengontrolan terhadap sumber daya agar mendapatkan hasil yang efektif. Apabila dikaitkan dengan dunia Pendidikan maka 
tujuan akhir tersebut adalah pada Pendidikan. Manajemen Pendidikan adalah suatu proses yang meliputi Perencanaan, selanjutnya pengorganisasian, kemudian pelaksanaan hingga pada pengawasan dalam mengelolah sumber daya yang ada, dimana hal tersebut dapat berupa man, money, materials, method, machines, market termasuk segala hal lain untuk mencapai suatu tujuan pendidikan yang efektif dan efisien. Perlu adanya sebuah rancangan serta perencanaan yang baik dalam mewujudkannya. Hal inilah yang dapat dikatakan sebagai manajemen.

Penempatan Sumber Daya Manusia pada Lembaga pendidikan merupakan suatu hal penting dalam manajemen pendidikan. Keputusan-keputusan untuk menyeleksi karyawan-karyawan yang berkualitas merupakan bagian penting dari Manajemen SDM yang berhasil. Dalam hal ini, SDM merupakan orang-orang yang bekerja didalam suatu organisasi atau bisa disebut sebagai karyawan. Bagi perusahaan, SDM merupakan suatu asset yang sangat berharga karena tanpa manusia maka setiap sumber daya dari perusahaan tersebut tidak akan memperoleh keuntungan atau laba bagi perusahaan tersebut. Manajemen SDM memiliki sebuah cara pandang dimana karyawan adalah manusia dan bukan mesin sehingga bukan semata-mata menjadi sumber daya dalam bisnis.

Sehingga tanpa adanya karyawan yang ahli dan memiliki motivasi tinggi, organisasi tersebut tidak akan berjalan dengan efektif. Disuatu sisi banyak perusahaan merekrut karyawan terbaikwalaupun harus merelakan untuk menghabiskan uang banyak agar mendapatkan karyawan yang terbaik karena dipandang sebagai investasi yang sangat enguntungkan bagi perusahaan.

Namun fakta terbaru yang terjadi saat ini meruntuhkan sebagian pandangan bahwa proses rekrutmen dan seleksi yang sangat sempurna sekalipun belum tentu menjamin sebuah perusahaan telah berhasil merekrut tenaga kerja yang sesuai dan diharapkan. Dari beberapa kajian masalah yang seringkali dihadapi perusahaan saat melakukan prosese seleksi calon karyawannya, ditemukan bahwa nilai yang baik berdasarkan pemeriksaan psikologis oleh tim rekrutmen, ternyata tidak memprediksikan keberhasilan dalam pekerjaan yang sebenarnya.

Perencanaan dan usaha pemenuhan SDM, perlu dilakukan secara professional terutama dalam melakukan rekrutmen sehingga dapat menentukan mutu serta kesuksesan perusahaan. Sehingga akan memperoleh SDM yang unggul untuk jangka waktu yang panjang.

Perencanaan sumber daya manusia strategik adalah staretgi bagaimana sebuah perusahaan dalam merencanakannya dengan tujuan memperoleh dan memanfaatkan setiap sumber daya manusia yang tentunya harus memperhatikan factor-faktor yang ada baik internal maupun external. Keadaan ini akan berpengaruh dan dipengaruhi pada sebuah perencanaan yang strategis bagi perusahaan dan juga merupakan 
keberlanjutan untuk keseluruhan manajemen manusia (MSDM). Sebagai langkah awal dimulai dengan mengamati bagaimana sebuah strategi dalam mengisi pekerjaan. Ada berapa banyak orang yang diperlukan dalam pekerjaan tersebut, bagaimana mereka dapat memilih berbagai macam keahlian dan kemampuan dari setiap orang. "Apa yang akan dilakukan pada proses rekruitmen tersebut jika ada campuran antara dari dalam dan luar perusahaan dalam proses baik melalui promosi dari dalam maupun adanya lowongan kerja yang tersedia untuk dari luar?"

Suatu cara untuk menetapkan kebutuhan karyawan untuk jangka waktu tertentu adalah lewat perencanaan sumber daya manusia (SDM). Kuantitas dan kualitas sangat penting dalam perencanaan ini, agar supaya perusahaan tidak mendapatkan karyawan atau sumber daya manusia yang over pada bidang tertentu atau yang langka pada bidang tertentu. Perencanaanpun sangat membantu perusahaan dalam menetapkan, pengelompokkan karyawan, pemberian arahan karyawan, pengendalian karyawan, pengadaan, kompensasi, pengembangan, pemeliharaan, pengintegrasian, pemberhentian atau kedisiplinan karyawan.

Dalam perusahaan diperlukan ketentuan/prasyarat untuk penentuan posisi. Ketika calon karyawan akan dilihat kemampuannya maka dibutuhkan ketajaman apalagi jika penentuannya dalam waktu yang singkat. Kejelian adalah kebutuhan agar kesalahan dalam penenmpatan ataupun dalam pemilhan karyawan tidak terjadi. Berbagai kualifikasi personil yang akan mengisi posisi atau jenjang jabatan seperti halnya bagi karyawan yang akan bertugas dibidang keuangan dibutuhkan ketelitian, atau bagi yang akan bertugas dibidang marketing maka dibutuhkan kemampuan berkomunikasi.

Penyeleksian untuk masing-masing perusahaan berbeda satusama lainnya. Namun ada kesamaan yang biasanya dipersyaratkan oleh perusahaan yaitu, pengalama, umur, Pendidikan, jenis kelamin, keahlian, kerjasama, bakat, tanggung jawab dan sebagainya. Dalam proses seleki bisa dilakukan dengan gabungan dari beberapa metode ataupun hanya menggunakkan satu metode seleksi saja. Tes praktek, suratlamaran, tes psikologi, penelitian merupakan metode seleksi yang dapat dilakukan.

Kesalahan dalam melakukan seleksi akan dapat berakibat cukup fatal baik dari segi keuangan perusahaan maupun individu yang bersangkutan, karena ketidakcocokan individu dengan pekerjaannya akan menyebabkan ketidakbahagiaan dan jeleknya kinerja yang ditunjukkan. Sehingga prosedur seleksi yang sangay ketat dilaksanakan oleh perusahaan-perusahaan yang punya kualitas. Penetapan jumlah orang ditetapkan sesuai dengan perencanaan yang ditetapkan perusahaan. Salah satu metode seleksi yang biasa digunakan adalah dengan melaksanakan pemeriksaan psikologis atau psikotes 
Hasil psikotes bukan merupakan pernyataan lulus atau tidaknya seorang calon, pada umumnya hasil psikotes berupa rekomendasi mengenai diri pelamar dikaitkan dengan tuntutan pekerjaan yang dilamarnya. Untuk mendapatkan keabsahan data dapat dilakukan dengan metode wawancara. Dengan perkataan lain, hasil psikotes dan wawancara merupakan salah satu pertimbangan di dalam keputusan seleksi karyawan

Pemeriksaan Psikologis di Indonesia kini banyak dipakai oleh Lembaga Pendidikan dengan jasa Psikolog. Untuk pekerjaan-pekerjaan tertentu pemeriksaan psikologispun dilakukan baik untuk non manajerial atau manajerial. Usaha pemeriksaan psikologis ini menjadi salah satu penyeleksian tenaga kerja. Hasil pemeriksaan psikologis ini menjadi penentu yang cukup besar. Kepercayaan pada hasil-hasil pemeriksaaan psikologis didasarkan pada pengamatan terhapa para tenaga kerja yang baru. Alhasil tenaga kerja yang direkomendasikan oleh para psikolog mempunyai pekerjaan yang bagus sehingga mendapatkan prestasi tetpai sebaliknya yang punya prestasi yang bagus kurang direkomendasikan oleh para psikolog (Ashar Sunyoto Munanda, 2003:29).

Global Art sebagai salah satu perusahaan pada bidang pendidikan di mana membantu peserta didik bahawa dengan seni dapat meningkatkan kreativitas anakanak sehinggan memungkinkan anak-anak ketika belajar, mengeksplorasi dan menemukan 'batas' baru dalam berpikir dan melakukan sesuatu secara berbeda. Sejak 1999, Global Art Creative Learning Methodology telah membina dan mengambangkan kreativitas anak-anak di seluruh dunia dengan visi menuju dunia yang lebih baik dengan merangkul kreativitas dan inovasi, menumbuhkan pikiran muda untuk menjadi imajinatif, kreatif, dan inovatif membuka potensi kratif anak-anak dan memperkaya hidup anak-anak, juga memiliki misi mempromosikan pemikiran kreatif dan inovatif dalam kehidupan anak-anak. Terapkan kecerdasan kreatif untuk memberikan produk, pelatihan, dan layanan terbaik berusaha untuk menjadi lebih efisien, efektif, dan memberikan lebih banyak.

Global Art sebagai perusahaan yang beregrak dalam bidang pendidikan memiliki manajemen pendidikan dalam menempatkan kualitas sumber daya manusia sesuai sengan kebutuhan Global Art, untuk itu dalam penempatan tenaga Staff Educational Adminiistrator dilaksanakan seleksi calon karyawan. Dalam hal pelaksanaan seleksi Calon Karyawan dengan menggunakan metode psikotes atau pemeriksaan psikologis. Pihak perusahaan mengharapkan agar proses seleksi dapat menyaring calon karyawan yang memiliki kualitas, serta mampu berprestasi sesuai dengan keinginan perusahaan.

Penelitian ini berisi tentang proses seleksi dari para calon karyawan untuk menempati posisi jabatanStaff Educational Administrator dengan rumusan masalah bagaimana cara mendapatkan calon karyawan sesuai dengan criteria untuk posisi jabatan Staff Educational Administrator dan Tujuan Penelitian ini adalah untuk 
memperoleh calon karyawan yang tepat yang cocok dengan tempatnya untuk memenuhi sumber daya manusia (SDM) pada posisiStaff Educational Administratordi Global Art Denpasar

\section{METODE PENELITIAN}

Menurut Sarlito Wirawan Sarwono (2003) pemeriksaan psikologik dilakukan oleh psikolog untuk melihat kondisi kejiwaan pasien yang akan diperiksa. Keadaan psikologik yang dimaksud adalah

1. Taraf kecerdasan

Menyangkut daya pikir yaitu IQ yang diuji pada para pelamar. Daya analisis dan kemampuan dalam numeric adalah kemampuan mental yang diuji pada pelaksanaan seleksi ini.

2. Sikap kerja

Sikap kerja di perusahaan yang berkaitam dengan pemeriksaan psikologik yaitu sistematik kerja, tempo kerja, ketelitian dan daya tahan kerja.

3. Faktor-faktor kepribadian lainnya

Keseimbangan emosi/EQ, kemampuan untuk menyesuaikan diri, minat/kesuakaan, kerjasama, hubungan interpersonal, kepercayaan diri, motivasi kerja, dan kepatuhan.

Dasar teori tes psikologi adalah bahwa kesehatan mental atau keadaan jiwacalon karyawan diukur atau diperiksa secara langsung lewat tingkah lakuny, karena tingkah laku adalah ekspresi atau karakter pribadinya.

Untuk menghasilkan data yang akurat yang sesuai dengan spesifikasi jabatan yang ditawarkan dalam proses seleksi calon karyawan digunakan metode interpretasi profil.

Analisis data dengan menggunakan metode interpretasi profil adalah jika data dikumpulkan menggunakkan alat teskemudian diolah dengan intrepretasi psikologi. Dalam hal ini seorang psikolog melihat dan menilai dari seperangkat tes yang sudah di skoring tanpa mengamati atau melakukan wawancara (Munandar, 2004 : 38)

Battery test merupakan kumpulan dari sejumlah tes yang biasa digunakan untuk mengukur berbagai atribut yang berbeda. Berikut ini adalah Battery test yang digunakan dalam proses seleksi berdasarkan aspek-aspek yang ingin diukur:

1. Kemampuan Intelektual

Aspek kemampuan intelektual, meliputi taraf kecerdasan atau potensi kecerdasan umum, pertimbangan social, kemampuan berfikir verbal, fleksibilitas berfikir, kemampuan abstraksi, kemampuan mengingat, logika berhitung, kemampuan 
analisa konseptual, berfikir komprehensif, kemampuan analisa konstruktif. Aspek kemampuan intelektual diungkap melalui battery test: CFIT ( Skala 3A \& Skala 3B)

2. Pola Kerja

Aspek pola kerja, meliputi kecepatan kerja (vitalitas kerja), kecermatan dan ketelitian kerja, kemantapan kerja, ketahanan kerja, kesigapan kerja dan orientasi terhadap kualitas hasil kerja. Aspek pola kerja diungkap melalui battery test: Kraeplin

3. Kepribadian kerja dan Sosial

Aspek kepribadian kerja dan social, meliputi motivasi berprestasi, penyesuaian diri, kedisiplinan, kepercayaan diri, kemandirian, kerjasama, hubungan interpersonal, sikap mempengaruhi orang lain, fleksibilitas, ketekunan, stabilitas emosi, dan tanggung jawab. Aspek kepribadian kerja dan social, diungkap melalui: DAM dan DISC

\section{HASIL DAN PEMBAHASAN}

1. Deskripsi Hasil Penelitian Kandidat Posisi Frontliner

a. Identitas subyek

Nama $\quad: \mathbf{R N}$

No. Pmrk : :008/PSI/02/10/2011

Tmp, Tgl. Lahir : Surabaya, 07/12/1988 Tgl. Pmrk : 02/10/2020

Jenis Kelamin : Perempuan

Tujuan : Seleksi

Pendidikan : S $1 \quad$ Jabatan : Administrator

\section{b. Hasil Tes}

Tabel 1. Hasil Tes Aspek Kemampuan Umum

\begin{tabular}{|c|l|c|c|c|c|c|}
\hline \multirow{2}{*}{ No Aspek Psikologis } & \multicolumn{5}{c|}{ Penilaian } \\
\cline { 5 - 7 } & & $\mathbf{1}$ & $\mathbf{2}$ & $\mathbf{3}$ & $\mathbf{4}$ & $\mathbf{5}$ \\
\hline I. KEMAMPUAN UMUM & & & $\mathbf{X}$ & & \\
\hline 1 & Taraf Kecerdasan & & & $\mathbf{X}$ & & \\
\hline 2 & Daya Tangkap & & & $\mathbf{X}$ & & \\
\hline 3 & Kemampuan Teoritis & & & $\mathbf{X}$ & & \\
\hline 4 & Kemampuan Terapan & & & $\mathbf{X}$ & & \\
\hline 5 & Daya Analisa & & & & $\mathbf{X}$ & \\
\hline 6 & Logika Berhitung & & $\mathbf{X}$ & & & \\
\hline 7 & Pertimbangan Sosial & & & $\mathbf{X}$ & & \\
\hline 8 & Pengetahuan Umum & & & & \\
\hline
\end{tabular}

Analisis : 
Potensi intelektual (IQ=94) umumnya berfungsi pada taraf yang cukup didukung kemampuan terapan yang berfungsi optimum, dan belum mampu menilai sesuatu dengan objektif, berdasarkan konsep praktis.

Tabel 2. Hasil Tes Aspek Pola Kerja

\begin{tabular}{|l|l|l|l|l|l|l|}
\hline \multirow{2}{*}{ No } & \multicolumn{5}{|c|}{ Aspek Psikologis } & \multicolumn{5}{c|}{ Penilaian } \\
\cline { 4 - 7 } & \multicolumn{1}{|c|}{$\mathbf{1}$} & $\mathbf{2}$ & $\mathbf{3}$ & $\mathbf{4}$ & $\mathbf{5}$ \\
\hline II. POLA KERJA & & & & $\mathbf{X}$ & \\
\hline 1 & Kecepatan dan Ketelitian Kerja & & & $\mathbf{X}$ & & \\
\hline 2 & Kesigapan & & & $\mathbf{X}$ & & \\
\hline 3 & Ketekunan dan Daya Juang & & & & $\mathbf{X}$ & \\
\hline 4 & Pengorganisasian Kerja & & $\mathbf{X}$ & & & \\
\hline 5 & Kedisiplinan Diri & & & $\mathbf{X}$ & & \\
\hline 6 & Orientasi Terhadap Kualitas Kerja & & & \\
\hline
\end{tabular}

Analisis :

$\mathrm{S}$ adalah orang yang suka bekerja sama dengan orang lain, bertindak lambat, tidak suka tantangan sehingga menghindari resiko, tidak banyak menuntut, tidak suka memerintah, pasrah, menggunakkan pertimbangan perasaan untuk mengambil keputusan,cenderung suka berhubungan dengan orang lain, cepat akrab, terbuka tapi tidak disiplin.

Tabel 3. Hasil Tes Aspek Kepribadian

\begin{tabular}{|c|c|c|c|c|c|c|}
\hline \multirow[b]{2}{*}{ No } & \multirow[b]{2}{*}{ Aspek Psikologis } & \multicolumn{5}{|c|}{ Penilaian } \\
\hline & & 1 & 2 & 3 & 4 & 5 \\
\hline \multicolumn{7}{|c|}{ III. KEPRIBADIAN } \\
\hline 1 & Keterampilan Interpersonal & & & & $\mathbf{X}$ & \\
\hline 2 & Penyesuaian Diri & & $\mathbf{X}$ & & & \\
\hline 3 & Keterbukaan Pikiran & & & $\mathbf{X}$ & & \\
\hline 4 & Kerja Sama & & & $\mathbf{X}$ & & \\
\hline 5 & Kepercayaan Diri & & & $\mathbf{X}$ & & \\
\hline 6 & Ambisi & & & $\mathbf{X}$ & & \\
\hline 7 & Fleksibilitas & & & $\mathbf{X}$ & & \\
\hline 8 & Kemandirian Kerja & & & $\mathbf{X}$ & & \\
\hline 9 & Inisiatif & & & & & \\
\hline
\end{tabular}


Analisis :

S adalah seorang yang suka bekerja sama dengan orang lain (koperatif), bertindak lamban, bertindak lambat, tidak suka tantangan sehingga menghindari resiko, tidak banyak menuntut, tidak suka memerintah, pasrah, menggunakkan pertimbangan perasaan untuk mengambil keputusan,cenderung suka berhubungan dengan orang lain, cepat akrab, terbuka tapi tidak disiplin.

Keinginan S untuk menghindari konflik dan menjaga perdamaian, membuat S menjadi sosok yang dikenal sebagai orang yang tenang dan santai.

Kelemahan S terlihat dari cara kerja/ perilaku yang lamban, tidak ad peningkatan/ statis, terlalu berhati-hati/ banyak pertimbangan, kepemimpinan yang malas/ ogah-ogahan, motivasi diri yang kurang, tidak memiliki ketegasan dan tidak mudah mengambil keputusan, takut mencoba sesuatu dan terlalu melindungi diri sendiri, tidak mau terlibat dalam resiko, membuat orang tidak percaya diri, takut pada perubahan, butuh kepastian dan jaminan, meyakinkan dan menyutujui sesuatu dengan waktu yang lama. Tetapi dibalik itu S mampu melaksanakan pekerjaan meski dibawah tekanan, bekerja secara konservatif dan stabil, punya perencanaan sebelum bekerja, punya pembawaan yang rapi, tertib dan teratur, punya pengaruh menstabilkan lingkungan kerja, memiliki pengaruh yang menyenangkan sehingga mampu berkeja sama dengan orang lain, bisa menjaga kedamaian dan menjadi pendamai bagi orang yang bermusuhan, dapat menyelesaikan masalah secara objektif.

Kekuatan :

1) Potensi intelektual (IQ=94) umumnya berfungsi pada taraf yang cukup didukung kemampuan terapan yang berfungsi optimum, dan belum mampu menilai sesuatu dengan objektif, berdasarkan konsep praktis.

2) Percaya akan kemampuan diri

3) Berorientasi pada kualitas hasil

4) Percaya akan kemampuan diri

5) Daya tahan kerja optimum, didukung vitalitas kerja dan perencanaan yang cukup baik, mampu mengarahkan vitalitas kerja mencapai prestasi optimum

6) Mampu mengontrol diri dengan cermat 
kelemahan :

1) Belum mampu menilai sesuatu dengan objektif, berdasarkan konsep praktis.

2) Perilaku yang lamban, statis, terlalu berhati-hati

3) Cenderung menghindari resiko

4) Meyakinkan dan menyetujui sesuatu dengan waktu yang banyak

5) Cenderung terlalu terstruktur / kaku

Kesimpulan Umum :

Mempertimbangkan kekuatan, dan kelemahan serta bagaimana vitalitas kerja diarahkan, diperkirakan sdr. Rince mampu mencapai prestasi kerja optimum sesuai tuntutan dan persyaratan jabatan, serta mengatasi hambatan, kelemahan dan masalah yang dialaminya.

Rekomendasi :

\begin{tabular}{|l|l|}
\hline TARAF IQ = 94 (Cukup) & $\begin{array}{l}\text { Keterangan : } \\
1=\text { Sangat Kurang, } 2=\text { Kurang, } 3=\text { Cukup, } \\
\end{array}$ \\
& $\begin{array}{l}4=\text { Baik } \\
5=\text { Sangat Baik }\end{array}$ \\
\hline $\begin{array}{l}\text { Rekomendasi : } \\
\text { [ ] A. Disarankan } \\
\text { [X] B. Dipertimbangkan } \\
\text { [ ] C. Tidak disarankan }\end{array}$ & Manado, 02 Oktober 2020 \\
\hline
\end{tabular}

\section{KESIMPULAN}

Berdasarkan hasil pemeriksaan psikologis sesuai dengan standar minimal yang telah ditentukan dengan bobot tertentu pada masing-masing dimensi psikologis. Kandidat untuk posisi jabatan Frontliner, yang diinterpretasi oleh calon Psikolog (CP) yang dibagi dalam kategori diantaranya disarankan, dipertimbangkan dan tidak disarankan. Dengan ini dapat disimpulkan bahwa proses seleksi telah berhasil dilaksanakan.Dari hasil penentuan bobot dan penghitungannya pada aspek-aspek dalam psikogram, diperoleh hasil sebagai berikut:

Kandidat untuk Posisi JabatanStaff Educational Administrator memperoleh skor 94 dan termasuk dalam kategori cukup, sehingga termasuk dalam rekomendasi dipertimbangkan.

\section{DAFTAR PUSTAKA}


Andang, 2014, Manajemen dan Kepemimpinan Kepala Sekolah, Konsep, Strategi, dan Inovasi Menuju Sekolah Efektif, Yogyakarta, Ar-Ruzz Media

Arikan \& Canan, 2015,'Effects of Organizational Structure at Outsourcing Companies to Operational Performance: a practice in logistics sector'. International Journal of Arts \& Sciences; Cumberland, vol. 8, no 4, hh. 263-272

Munandar, S. A., 2012, Psikologi Industri dan Organisasi. Jakarta: Penerbit Universitas Indonesia

Fattah, N, Landasan Manajemen Pendidikan, Bandung: PT Remaja Rosda karya, 2000

Mardhiah, R., 2010, Psikologi Umum. Pekanbaru, UR Press 